\title{
The Sharypic PhotoWall at the Royal Ontario Museum: An experiment in real-time crowdsourcing
}

\author{
W. Ryan Dodge \\ Royal Ontario Museum \\ Toronto, Canada \\ ryand@rom.on.ca / @wrdodger
}

\author{
Laura Haapio-Kirk \\ Sharypic \\ Paris, France \\ laura.Ihk@gmail.com / @LauraLHK
}

\section{INTRODUCTION}

The Royal Ontario Museum's (ROM) Friday Night Live events are always busy on social media platforms, and last fall the museum was interested in finding a way to display crowdsourced photos in real time. As social media is the main promotional driver of these events we were interested in making the onsite social media experience more engaging and more visual than by using traditional twitter walls. Sharypic's service was ideal for this purpose and this collaboration is the first of its kind in the cultural sector, on this scale.

\section{THE 'CROWD' TAKES OVER}

Over the eight-week Friday Night Live series during the Fall of 2012, 947 contributors shared over 2,000 photographs, broadcast on one of the biggest interior walls of the museum for all to see in real-time. Sharypic allows our followers to post photos of their experience and we receive realtime, visual feedback that the museum can use to update offerings and make the visitor experience truly social. The Sharypic - ROM demonstration will look at the challenges, goals, and results of the collaboration. We will analyse visitor feedback gained at the ROM and in other museum contexts, to find out exactly how the PhotoWall affects visitor experience in terms of relationships with museum objects and general feelings towards the museum as a whole. We will look at comments such as the one below, analysing keywords and sentiment.

\subsection{Visitors react}

"As soon as I saw the photo wall at the ROM I knew I needed to get my tweet up there. It gave me a chance to share my experience and made me feel like a star. Dedicating that space to visitors' comments let me know the ROM truly valued how we were enjoying ourselves, and fostered our habit of tweeting and sharing information about the event." www.emmajenkin.com / @indeedemma

\section{SHARYPIC AND MUSEUMS}

Sharypic want to develop relationships with museums, with the goal of enhancing visitor experience, making museums more engaging, open, and accessible through visitor photography. The implications of this technology for bringing cultural institutions up-to-date are fascinating as we start to incorporate the social, digital world into the fabric of visitor experience, and adapt to the way many people now mediate the world through images. Sharypic think that allowing visitors to have a sense of ownership over exhibits through photography may be a step in the right direction. With deep feedback from cultural institutions like the ROM, Sharypic has developed in response to museum needs, adding new features as more is understood about how visitors interact via photography. The demonstration will highlight key features which have developed in parallel with feedback, such as content moderation and options for customisation. We will discuss the potential issues that can arise when museums embrace such technology and look at how technology can adapt to the specific needs of cultural institutions. 


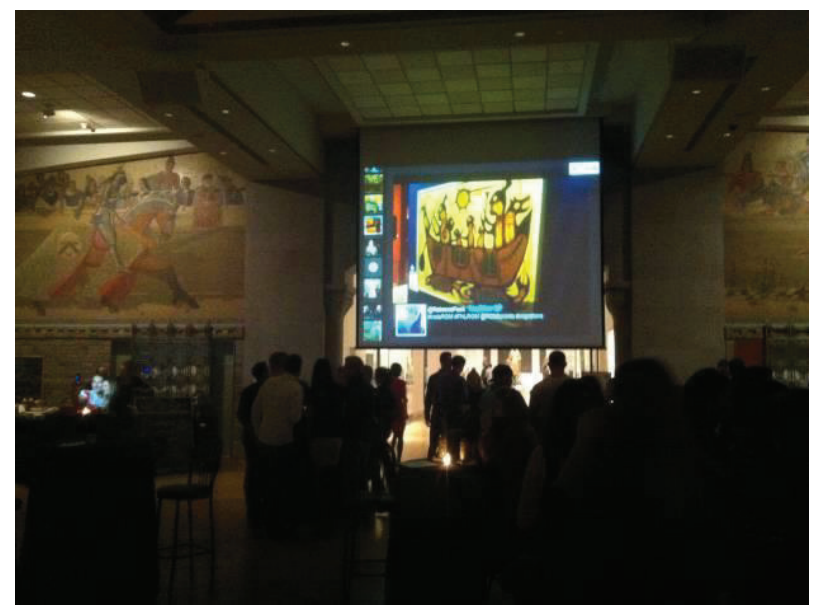

Figure 1: The photo wall in action at the ROM

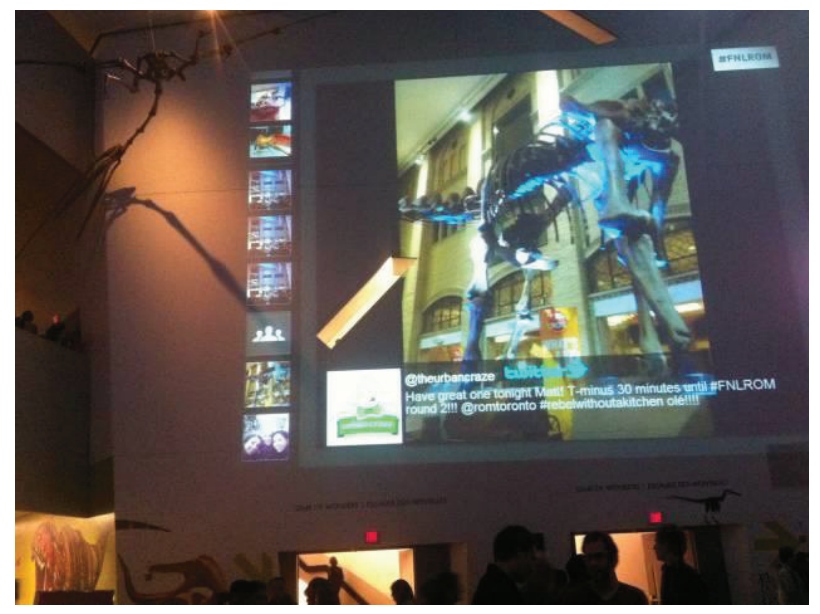

Figure 2: The photo wall on the largest white space in the ROM

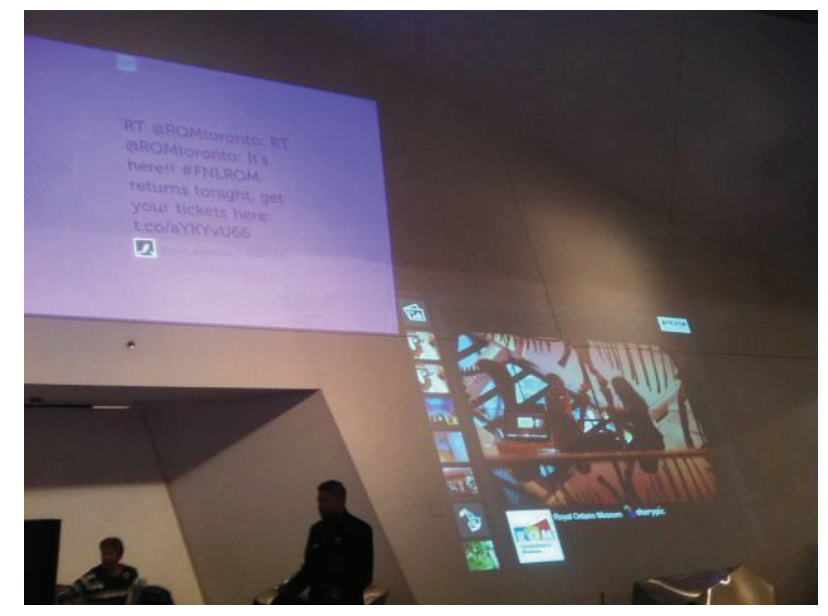

Figure 3: The photo wall with traditional Twitter wall

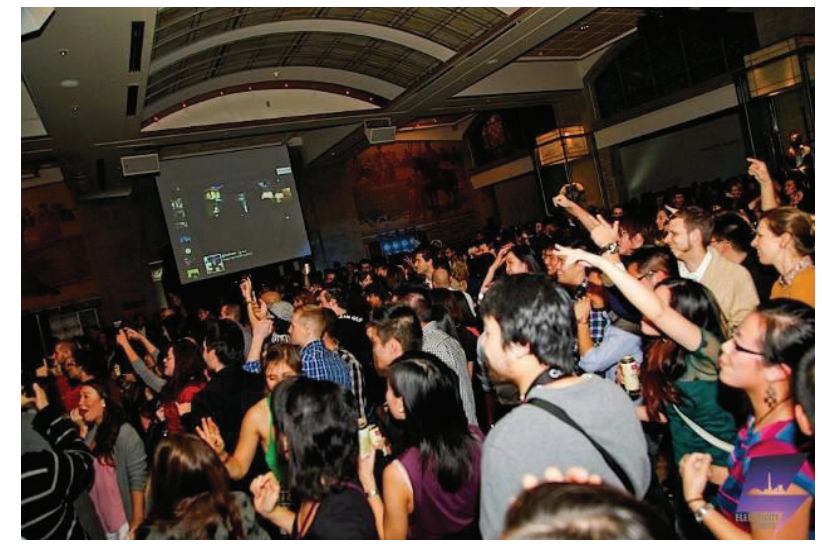

Figure 4: The photo wall on the dance floor 